\title{
EVALUANDO EVIDENCIAS HUMANAS EN LA MARGEN BOSQUE-ESTEPA ( $>900$ MSNM) DE PATAGONIA CENTRAL: CUEVA DE PUNTA DEL MONTE (REGIÓN DE AISÉN, CHILE)
}

\author{
AMALIA NUEVO DELAUNAY", CÉSAR MÉNDEZ", OMAR REYES ${ }^{* * * *} \&$ VALENTINA TREJO"****
}

\section{RESUMEN}

En este trabajo se presentan los resultados de las investigaciones arqueológicas llevadas a cabo en el sitio de la Cueva de Punta del Monte (Región de Aisén, Patagonia Central). La evidencia fue obtenida a través de recolecciones superficiales, relevamiento del arte rupestre y una excavación restringida. Pese a que es necesario considerar con precaución la información ${ }^{14} \mathrm{C}$ de este sitio, los resultados sugieren que las evidencias se enmarcan en los últimos 5.660 años calibrados. Los datos obtenidos son discutidos a escala regional con la intención de ejemplificar la ocupación de sectores donde colindan ambientes disímiles como son el bosque y la estepa. A partir de estos resultados preliminares, se discute la posibilidad que las evidencias estén reflejando una situación de marginalidad en términos geográficos.

PALABRAS CLAVE: ocupación de espacios marginales, cazadores recolectores, arte rupestre, Patagonia central.

\section{ASSESSING HUMAN EVIDENCE IN THE FOREST-STEPPE MARGIN (>900 MASL) OF CENTRAL PATAGONIA: CUEVA DE PUNTA DEL MONTE (AISÉN REGION, CHILE)}

\footnotetext{
ABSTRACT

This paper presents the results of archaeological investigations conducted in Punta del Monte cave site (Aisén Region, Central Patagonia). The evidence was obtained through surface collections, a rock art survey and a test excavation. Despite caution is needed when considering ${ }^{14} \mathrm{C}$ information from this site, results suggest that the evidence is framed within the last 5,660 calibrated years. Data are discussed in a regional scale and intended to exemplify the occupation of areas where different environments, such as the forest and steppe, adjoin. Based on these preliminary results, we discuss the possibility that evidence is reflecting a situation consistent with geographical marginality.

KEY WORDS: occupation of marginal spaces, hunter-gatherers, rock art, Central Patagonia.

* Departamento de Antropología, Facultad de Ciencias Sociales, Universidad Alberto Hurtado. Almirante Barroso 10, Santiago, Chile. anuevodelaunay@gmail.com.

** Departamento de Antropología, Facultad de Ciencias Sociales, Universidad de Chile. Ignacio Carrera Pinto 1045, Nuñoa, Santiago, Chile.cmendezm@uchile.cl.

**** Centro de Estudios del Hombre Austral, Instituto de la Patagonia, Universidad de Magallanes. Av. Bulnes 01890, Punta Arenas, Chile. omarreyesbaez@gmail.com.

***** Arqueóloga. Alonso Pinzón 6485, Las Condes, Santiago, Chile. valentinatrejovidal@gmail.com.
} 


\section{INTRODUCCIÓN}

Los asentamientos humanos de áreas marginales brindan un escenario singular para entender procesos de ocupación de espacios de forma global y comprender la delimitación de territorios en los grupos de cazadores recolectores. En este trabajo se entiende la marginalidad en su acepción geográfica, la que implica que el menor uso de un área estará dado por la distancia hacia centros nucleares donde los grupos humanos habitaron de forma más recurrente (Borrero, 2004). La evaluación de marginalidad puede ser discutida desde distintos parámetros, por ejemplo la incorporación de nuevos espacios (Anderson, 2003), flujos de materias primas (Barberena et al., 2011), series de fechados radiocarbónicos (Neme \& Gil, 2008; Williams et al., 2008), la arqueofauna en escala regional (Borrero 2004), entre otros. En este trabajo optamos por usar la escala de sitio. Proponemos que seleccionando sitios arqueológicos en áreas clave de acuerdo a la diversidad ecológica de la región, es posible caracterizar aspectos puntuales del uso del espacio, enfatizando sobre la heterogeneidad de las manifestaciones humanas. Para definir un área como marginal debiéramos esperar (1) baja frecuencia ocupacional, (2) discontinuidad de las ocupaciones humanas y (3) ausencia de campamentos base (Veth, 1993; Borrero, 2004; Neme \& Gil, 2008). Trabajamos el caso de Patagonia Central, donde el bosque operó -al menos en algunos momentos- como margen de las ocupaciones humanas más frecuentes en la estepa (Méndez et al., 2013a). Por sus características, el bosque montano de Aisén ha sido definido anteriormente como una barrera biogeográfica (Méndez \& Reyes, 2008). Algunas de estas observaciones han sido previamente descritas para otros sitios en la estepa de la región como El Chueco 1 (Méndez et al., 2011). Sin embargo, la posición frente al límite actual del bosque/estepa del sitio de la Cueva de Punta del Monte, nos brinda una instancia singular para poder evaluar este problema con un nuevo conjunto de datos.

La Cueva de Punta del Monte constituye una localidad arqueológica largamente conocida que fue publicada inicialmente por Felipe Bate (1970a, 1970b). En estos trabajos se realizó una somera descripción del sitio, con especial énfasis en el arte rupestre. Otras referencias al arte rupestre del sitio se pueden encontrar en Sade (2008). En los últimos años, investigaciones en la región han enfocado su interés hacia el área desde una perspectiva regional, llevando a cabo nuevos estudios en este sitio. Los trabajos se han enmarcado en prospecciones realizadas en áreas de estepa y transición bosque estepa, con el fin de entender la distribución y características espaciales del material arqueológico en el norte de la región de Aisén (Méndez et al., 2013a, 2013b).

\section{EL ÁREA DE ESTUDIO Y EL SITIO}

El sitio de la Cueva de Punta del Monte (4525'15,14" S; 71³3'13,24" W; 928 msnm) se encuentra ubicado en el centro-este de la Provincia de Coyhaique, localidad de Coyhaique Alto (Región de Aisén, Patagonia) (Fig. 1). El clima del área es de tipo templado xérico, con temperaturas mínimas y máximas que oscilan entre los $2,5^{\circ} \mathrm{C}$ y los $14,2^{\circ} \mathrm{C}$ respectivamente y con una precipitación media anual de $837 \mathrm{~mm}$. La formación vegetal local se describe como un piso de vegetación de estepa mediterráneatemplada de Festuca pallescens y Mulinum spinosum (Luebert \& Pliscoff, 2006). No obstante, como el nombre lo indica, la localidad de Punta del Monte se caracteriza por ser el lugar más elevado en los alrededores donde se da una cobertura boscosa, correspondiente al piso de vegetación de matorral arborescente caducifolio templado de Nothofagus antarctica y Berberis microphylla (Luebert \& Pliscoff, 2006). Esta particular disposición marcada que tiene el límite bosque/estepa en esta localidad presenta una oportunidad singular para evaluar las conductas en ambientes de márgenes.

En esta localidad se han registrado varios sitios, entre los que destaca un extenso taller (Bate, 1970b) y escasos hallazgos aislados recuperados en una prospección sistemática (Méndez et al., 2013b). El taller de Punta del Monte corresponde a un área de 1,2 ha (1.030 msnm) donde se concentra abundante material lítico en superficie por acción de la deflación. F. Bate llevó a cabo extensas colecciones de material donde destacó la presencia de láminas (hojas) retocadas, raspadores frontales, raederas, muescas, grandes piezas bifaciales, cabezales líticos triangulares (Bate 1970b, 1982) a lo que podemos sumar núcleos, cepillos, manos de moler, bolas; más los abundantes desechos de talla en variadas fases que componen el conjunto de superficie. Cuatro sondeos estratigráficos no han producido material 


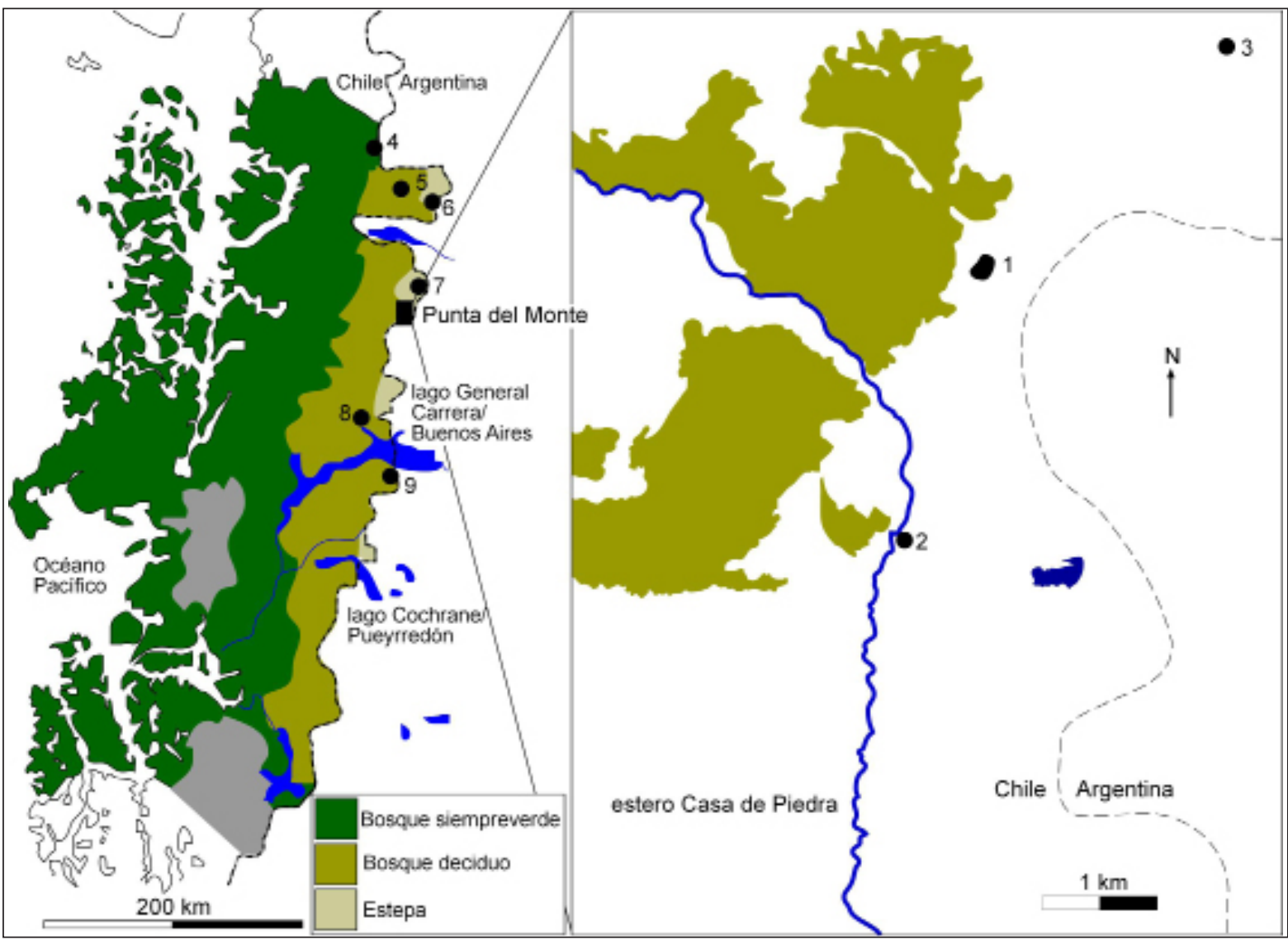

Fig. 1. Área de estudio y sitios nombrados en el texto: 1. Taller Punta del Monte; 2. Cueva Punta del Monte; 3. Baño Nuevo-9; 4. Lago Verde 1 y 2; 5. Alero Las Quemas; 6. El Deshielo; 7. Baño Nuevo-1; 8. Área Río Ibáñez; 9. Área Río Jeinemeni. La imagen de detalle (derecha) muestra los límites entre el bosque y la estepa abierta.

arqueológico como para definir una ocupación discreta.

El sitio de la Cueva de Punta del Monte (RAiCO-3 o PM-3 según Bate 1970a) corresponde a un abrigo rocoso labrado fluvialmente sobre un afloramiento de toba volcánica, inmediatamente al Este del estero Casa de Piedra (Fig. 2) que corre por una falla. La cueva, cuya abertura se orienta hacia el W, presenta un área aproximada de $405 \mathrm{~m}^{2}$ (45 m sentido N-S y 9 m sentido E-W), una altura máxima aproximada de 2,5 m y una pendiente suave $\left(<5^{\circ}\right)$ en la mayor parte del reparo (Fig. 3). Sondeos practicados por Bate (1970a) revelaron que aunque los depósitos estaban fuertemente afectados por el acarreo fluvial, existían indicaciones de continuas ocupaciones esporádicas.

Un conjunto de agentes formacionales afec- tan a la cueva y al registro arqueológico en ella. A continuación se presenta un listado de éstos y sus efectos.

Curso fluvial: la proximidad de la cueva al escurrimiento del estero Casa de Piedra (hoy en día a escasos 4 metros en algunos sectores) ha tenido un efecto sobre la cantidad de material superficial y las asociaciones espaciales del material en el sitio. No es posible indicar un marco temporal para este efecto, aunque pudo observarse guijarros en estratigrafía que sugieren el ingreso del curso en algunos momentos.

Friabilidad de la roca de caja: La toba que conforma la cueva es muy frágil, lo que ha generado el colapso de partes de las paredes y el techo, haciendo que los fragmentos de toba correspondan a una de las principales partículas sedimentarias de la cueva. 


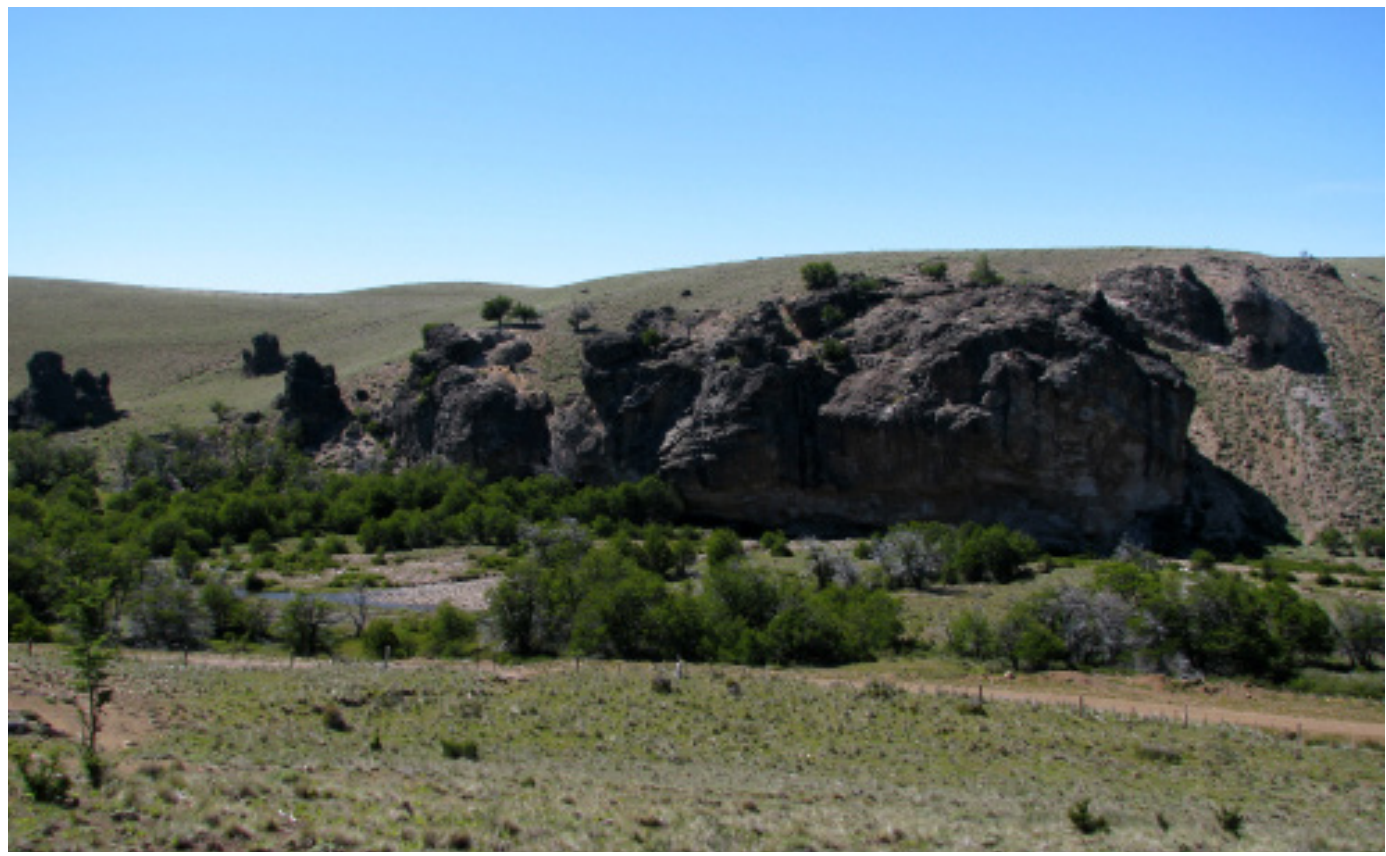

Fig. 2. Vista (Este) del sitio Cueva Punta del Monte.

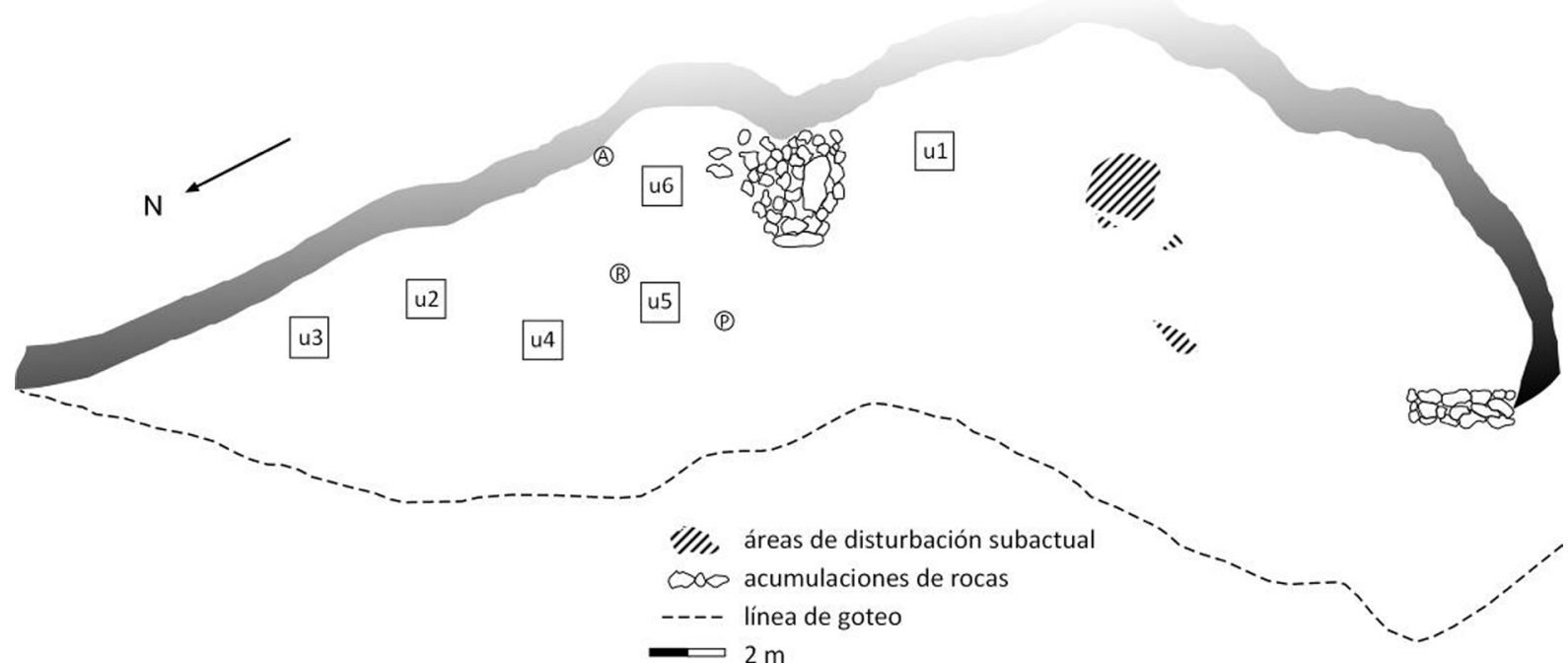

Fig. 3. Planta de la Cueva Punta del Monte con ubicación de unidades de muestreo y estructuras subactuales. U: unidades mencionadas en el texto, A. ápice de punta de proyectil, R: raspador, P: percutor con pigmento. 
Dado que éste es un efecto continuo a lo largo del tiempo, ha tenido consecuencias importantes sobre la integridad de las manifestaciones rupestres en el sitio.

Acción antrópica reciente: Se presenta en la forma de varias excavaciones de propósito desconocido, coleccionismo de piezas líticas, fractura intencional de paneles con arte rupestre, graffiti, acomodaciones de rocas (corrales, pircados y acumulaciones) y la realización de actividades de tala y quema. Todas estas actividades son en general muy intensas y sostenidas en el tiempo ${ }^{5}$.

\section{OBJETIVOS Y MÉTODO}

Este trabajo compila los resultados de nuevas investigaciones recientes llevadas a cabo en el sitio de la Cueva Punta del Monte. Con el objetivo de comprender la ocupación humana del sitio, se llevaron a cabo una serie de muestreos, superficiales y en estratigrafía, así como también el registro del arte rupestre. Se incluye un intento por precisar cronológicamente las ocupaciones humanas. Finalmente, el objetivo último es discutir las evidencias del sitio en el marco de las ocupaciones en distintos ambientes de Aisén al oriente de los Andes.

Los métodos analíticos en laboratorio incluyeron el análisis del material lítico, el uso de fechados ${ }^{14} \mathrm{C}$ para establecer la profundidad temporal del registro, el análisis de procedencia de materias primas líticas, y el relevamiento del arte rupestre.

El sedimento de superficie recuperado en las áreas de muestreo fue procesado en el laboratorio, producto del alto grado de fragmentación que las evidencias visibles presentaban. Éste fue tamizado con dos grosores diferentes (1 y $2 \mathrm{~mm}$ ). El material recuperado (lítico, óseo, malacológico, vidrio y pigmento) sólo fue cuantificado. Sin embargo, en el caso del material lítico, se pudieron clasificar las materias primas, tipos de artefactos y presencia/ ausencia de talón. También en el caso del material óseo, a pesar que los fragmentos no pudieron ser identificados a nivel anatómico, ni a nivel taxonómico (salvo excepciones), se optó por llevar a cabo una cuantificación básica para discriminar restos de roedores y aves, de los restos de mamíferos medianos a

5 Esta situación ha motivado una denuncia ante el Consejo de Monumentos Nacionales por los graves daños al patrimonio protegido por la Ley 17.288. mayores, así como presencia/ausencia de quemado como indicador relativo de acción humana.

El uso de fechados ${ }^{14} \mathrm{C}$ AMS buscó posicionar temporalmente las ocupaciones humanas. Para ello se corrigieron los resultados convirtiendo las edades a años calibrados antes del presente (cal AP) con el programa OxCal 4.2 (Bronk Ramsey, 2009), con la curva ShCal13 (Hogg et al., 2013).

Por último, se realizaron análisis geoquímicos de muestras de obsidiana para establecer procedencia por medio de la técnica ICP-MS (Laboratory for Environmental Geochemistry, University of Colorado) que define elementos traza y permite su comparación con muestras de las fuentes, siguiendo experiencias previas en la región (Méndez et al., 2012; Stern et al., 2013).

En el caso del arte rupestre el análisis contempló los distintos aspectos metodológicos utilizados en trabajos llevados a cabo en otras áreas de Patagonia (Re et al., 2006-2007). Así, para discutir la densidad de representaciones rupestres se tomó la medida correspondiente a la cantidad de elementos y de motivos. Los primeros son entendidos como la segmentación inicial que distingue unidades discretas en el espacio del soporte (Re et al., 2006-2007). Éstos luego fueron agrupados en motivos simples o compuestos (Aschero \& Martel, 2003-2005; Gradín, 1978). Los grupos de motivos observados son: Abstractos, Pisadas, Guanacos y Manos (Re 2010). "Abstractos" pueden comprender círculos, semicírculos, líneas curvas, quebradas, rectas y sinuosas, punteados, radiales, trazos, caóticos, cruces, espirales, peiniformes, reticulados, subcirculares y geométricos complejos. Las "pisadas" pueden ser tridígitos (huella de choique y aves), de felino, de guanaco, de caballo y humana (Re et al., 2006-2007).

Finalmente, se considera que, tanto la cantidad de elementos como de motivos, representan un número mínimo, considerando el alto nivel de deterioro que presenta la evidencia rupestre del sitio.

\section{RESULTADOS}

\section{Estratigrafía y cronología}

En la Unidad de muestreo ${ }^{\circ} 1$ se llevó a cabo una excavación de $1 \mathrm{~m}^{2}$, por niveles artificiales de 10 $\mathrm{cm}$, alcanzando una profundidad máxima de $90 \mathrm{~cm}$. 


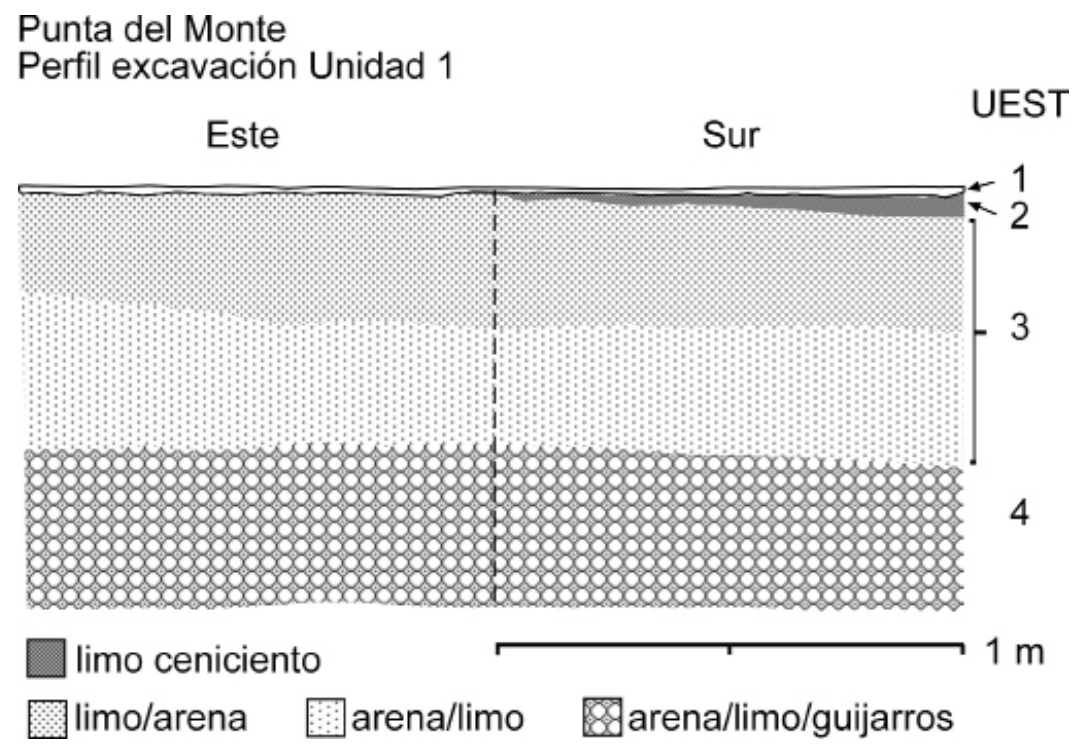

Fig. 4. Secuencia estratigráfica, unidad de excavación.

La secuencia estratigráfica del sitio (Fig. 4) se inicia con una unidad (UEST1) de sedimentos superficiales sueltos que incluyen limos, arenas y fragmentos de toba, colapsados de las paredes y techo de la cueva. Esta unidad contiene material arqueológico, principalmente subactual, que incluye vidrio, metal, restos malacológicos, madera, hueso, líticos y fecas. Todo este material se registra en frecuencias muy bajas. La siguiente unidad estratigráfica (UEST2), representada principalmente en la pared sur de la Unidad 1, está compuesta por sedimentos correspondientes a limos cenicientos poco compactos. Esta unidad también contiene material subactual. La unidad estratigráfica 3 (UEST3) se compone de limos, arenas y tobas angulosas. Posee dos sub-unidades: una superior conformada por limos con poca arena y de color café claro; y una inferior con mayor proporción de arenas y de color más oscuro. Por último, la unidad estratigráfica 4 (UEST4) está compuesta de arenas y guijarros de varios tamaños de origen fluvial, mezclados con tobas producto de la degradación de las paredes y el techo de la cueva. Las unidades inferiores acusan los efectos de la modelación del estero Casa de Piedra en la conformación del depósito de la cueva. Las unidades estratigráficas 3 y 4 no produjeron material arqueológico en excavación.

En vistas que la excavación no permitió identificar ocupaciones humanas discretas, se se- leccionó una muestra de carbón recuperada de la unidad estratigráfica 2 , cuya posición cercana a la superficie pudiera acercarse a un fechado mínimo para las ocupaciones del sitio. Consecuente con la mezcla de evidencias subactuales y arqueológicas de la superficie, la edad ${ }^{14} \mathrm{C}$ arrojó un resultado de 240 \pm 34 años AP valor difícilmente discernible de una ocupación contemporánea al calibrarla a 2-sigma (Tabla 1). En vistas de ello, se eligió un resto óseo superficial identificado taxonómicamente como Lama guanicoe, en el entendido que su presencia pudiera sugerir alguna probabilidad de incorporación humana, aunque no puede descartarse su ingreso a la cueva por muerte natural. El fechado arrojó una edad de $4.980 \pm 40$ años AP, asignación cronológica que debe considerarse con mucha cautela, aun cuando es congruente con las manifestaciones rupestres más conspicuas en el sitio. Estos dos fechados se suman a un tercero recuperado en el cercano taller, que arrojó un valor de $1.330 \pm 30$ años AP. Esta edad se considera mínima por cuanto todo el conjunto lítico es superficial y la muestra de madera parcialmente quemada se obtuvo en estratigrafía, a poca profundidad de la superficie. Al igual que en el caso de las fechas anteriores, ésta también debe considerarse con mucha cautela por cuanto podría ser producto de fuego no intencional. En conjunto, estos datos, si bien no otorgan una significativa 
Tabla 1. Edades ${ }^{14} \mathrm{C}$ AMS obtenidas en la localidad Punta del Monte

\begin{tabular}{|c|c|c|c|c|c|c|}
\hline Sitio & Código & $\begin{array}{c}\text { Edad }{ }^{14} \mathrm{C} \\
\text { años AP }\end{array}$ & $\delta^{13} \mathrm{C}$ & $\begin{array}{c}1 \sigma \text { años cal } \\
\text { AP }\end{array}$ & Material & Procedencia \\
\hline \multirow{2}{*}{ Taller } & BETA 295194 & $1.330 \pm 30$ & Insuficiente & $1.270-1.190$ & $\begin{array}{c}\text { Madera parcialmente } \\
\text { quemada }\end{array}$ & Unidad 1 (20-30 cm) \\
\hline \multirow{2}{*}{ Cueva } & AA94561 & $246 \pm 34$ & $-26,5$ & $300-150$ & $\begin{array}{c}\text { Carbón vegetal } \\
\text { (espícula) }\end{array}$ & $\begin{array}{c}\text { Unidad 1, UEST 2 (5 } \\
\mathrm{cm})\end{array}$ \\
\cline { 2 - 7 } & BETA 297426 & $4.980 \pm 40$ & $-20,1$ & $5.710-5.610$ & $\begin{array}{c}\text { Hueso (Lama } \\
\text { guanicoe) }\end{array}$ & Superficie \\
\hline
\end{tabular}

precisión temporal de la ocupación del área Punta del Monte y sus sitios, en conjunto pueden sumar a la comprensión regional de la ocupación humana de Aisén.

\section{Conjunto lítico}

La evidencia lítica en la cueva de Punta del Monte es muy escasa, principalmente por el coleccionismo subactual, que ha hecho del depósito de superficie un discreto sector con dispersión de material muy pequeño y fragmentario. El coleccionismo ha estado enfocado sobre las categorías líticas de mayor formatización (casi totalmente ausentes en el sitio), como puede constatarse en colecciones particulares revisadas someramente, donde destacan, por ejemplo, las láminas u hojas.

En vistas de esta situación, la recolección superficial fue llevada a cabo para tratar de identificar de forma indirecta algunas de las conductas realizadas en el sitio por medio del análisis de desechos. La primera intención de este análisis fue determinar el nivel de fragmentación de los desechos y microdesechos a fin de establecer la representatividad de las piezas en el contexto. La Tabla 2 muestra una muy significativa fragmentación de las evidencias, la que se manifiesta en el porcentaje de piezas sin talón por materia prima y en cada unidad muestreada. La fragmentación total de la muestra es de un $78 \%$ y en casos como el basalto y otras rocas ésta supera el $87 \%$. Por su parte, en términos de distribución espacial, la unidad 3 (al extremo NE del reparo) es la que muestra mayor fragmentación en todas sus materias primas. La alta incidencia de fragmentación se atribuye principalmente al pisoteo sobre el sustrato duro.

Las categorías tecnológicas representadas son sólo desechos de talla y microdesechos de retoque. Únicamente se pudo identificar una lasca de adelgazamiento bifacial, lo que sugiere que esta tarea fue prácticamente inexistente; como también lo fue la producción de otros artefactos, para los cuales se esperaría mayor cantidad y diversidad de desechos. Tampoco se registraron cepillos, denticulados u otras herramientas (o sus fragmentos) previsibles en un contexto adyacente a un bosque.

Los trabajos realizados en el sitio sólo permitieron registrar un fragmento distal de un pequeño raspador frontal y un ápice de punta de proyectil de sección muy baja (Fig. 3), concordante con la morfología de una pequeña punta triangular.

Si bien es cierto el estado de los conjuntos del sitio no permite sugerir aspectos funcionales, sí permite descartar una presencia muy redundante y/o sostenida que habría producido mayor cantidad y diversidad de basuras de producción de instrumental.

En cuanto a las materias primas representadas en el sitio, éstas no son muy variadas (Tabla 2) y evidencian distintas calidades para la talla. La mayor diversidad se dio al interior de las sílices donde se identificaron tres distintos tipos de similar calidad. Llama la atención la ausencia total de la variedad de sílice naturalmente disponible en el Taller de Punta del Monte, localizado a escasos $3 \mathrm{~km}$ de este sitio, aun cuando evidencias talladas de esta roca fueron encontradas en el equidistante Baño Nuevo 28. Se desconoce la procedencia de la mayoría de las rocas puesto que no se han realizado búsquedas orientadas a caracterizar los recursos líticos. Sin embargo, de los desechos de talla de obsidiana negra de superficie, se seleccionaron dos para análisis geoquímicos (Tabla 3). Sus resultados son consistentes con las variedades PDA1 y PDA2 de Pampa del Asador, los que coinciden con los resultados de las muestras analizadas en el vecino taller (Stern et al., 2013).

\section{Conjunto arqueofaunístico}

El material óseo recuperado de la superficie del sitio es muy fragmentario y se presenta en baja 
Tabla 2. Material lítico recolectado por unidad de muestreo (TG: tamiz grueso, TF: tamiz fino, CT: piezas con talón, ST:piezas sin talón, Fr\%: porcentaje de piezas fracturadas).

\begin{tabular}{|c|c|c|c|c|c|c|c|c|c|c|}
\hline \multirow{2}{*}{\multicolumn{2}{|c|}{ Recursos líticos }} & \multirow{3}{*}{$\begin{array}{c}\text { Unidad } 2 \\
4 \\
\end{array}$} & \multicolumn{2}{|c|}{ Unidad 3} & \multicolumn{2}{|c|}{ Unidad 4} & \multicolumn{2}{|c|}{ Unidad 5} & \multirow{3}{*}{$\begin{array}{c}\text { Unidad } 6 \\
1\end{array}$} & \multirow{3}{*}{$\begin{array}{r}\text { Total } \\
17 \\
\end{array}$} \\
\hline & & & \multirow{2}{*}{$\begin{array}{c}\text { TG } \\
4\end{array}$} & \multirow{2}{*}{$\begin{array}{c}\text { TF } \\
3 \\
\end{array}$} & \multirow{2}{*}{$\begin{array}{c}\text { TG } \\
2\end{array}$} & \multirow{2}{*}{$\begin{array}{c}\text { TF } \\
1 \\
\end{array}$} & \multirow{2}{*}{$\begin{array}{c}\text { TG } \\
0\end{array}$} & \multirow{2}{*}{$\begin{array}{c}\text { TF } \\
2 \\
\end{array}$} & & \\
\hline \multirow{3}{*}{ Andesita } & CT & & & & & & & & & \\
\hline & ST & 5 & 13 & 12 & 6 & 1 & 24 & 4 & 3 & 68 \\
\hline & Fr\% & 55,5 & 76,5 & 80 & 75 & 50 & 100 & 66,7 & 75 & 80 \\
\hline \multirow{3}{*}{ Basalto } & $\mathrm{CT}$ & 10 & 19 & 4 & 1 & 0 & 3 & 2 & 4 & 43 \\
\hline & ST & 19 & 161 & 83 & 8 & 1 & 8 & 4 & 8 & 292 \\
\hline & Fr\% & 65,5 & 89,4 & 95,4 & 88,9 & 100 & 72,7 & 66,7 & 66,7 & 87,2 \\
\hline \multirow{3}{*}{ Sílice clara opaca } & CT & 3 & 12 & 4 & 2 & 0 & 2 & 0 & 2 & 25 \\
\hline & ST & 3 & 26 & 9 & 2 & 2 & 4 & 1 & 3 & 50 \\
\hline & Fr\% & 50 & 68,4 & 69,2 & 50 & 100 & 66,7 & 100 & 60 & 66,7 \\
\hline \multirow{3}{*}{ Sílice translucida } & CT & 13 & 6 & 3 & 5 & 1 & 5 & 4 & 3 & 40 \\
\hline & ST & 13 & 10 & 3 & 9 & 3 & 18 & 5 & 12 & 73 \\
\hline & Fr\% & 50 & 62,5 & 50 & 64,3 & 75 & 78,3 & 55,6 & 80 & 64,6 \\
\hline \multirow{3}{*}{ Sílice opaca rojiza } & $\mathrm{CT}$ & 7 & 11 & 1 & 4 & 1 & 4 & 1 & 3 & 32 \\
\hline & ST & 10 & 28 & 15 & 5 & 3 & 14 & 2 & 3 & 80 \\
\hline & Fr\% & 58,8 & 71,8 & 93,8 & 55,6 & 75 & 77,8 & 66,7 & 50 & 71,4 \\
\hline \multirow{3}{*}{ Obsidiana negra } & CT & 1 & 1 & 0 & 2 & 0 & 0 & 1 & 0 & 5 \\
\hline & ST & 0 & 0 & 1 & 1 & 0 & 1 & 0 & 1 & 4 \\
\hline & Fr\% & 0 & 0 & 100 & 33,3 & - & 100 & 0 & 100 & 44,4 \\
\hline \multirow{3}{*}{ Otros } & $\mathrm{CT}$ & 1 & 2 & 0 & 1 & 1 & 0 & 0 & 1 & 6 \\
\hline & ST & 4 & 15 & 10 & 8 & 1 & 1 & 1 & 2 & 42 \\
\hline & Fr\% & 80 & 88,2 & 100 & 88,9 & 50 & 100 & 100 & 66,7 & 87,5 \\
\hline \multirow{3}{*}{ Total } & $\mathrm{CT}$ & 39 & 55 & 15 & 17 & 4 & 14 & 10 & 14 & 168 \\
\hline & ST & 54 & 253 & 133 & 39 & 11 & 70 & 17 & 32 & 609 \\
\hline & Fr\% & 58,1 & 82,1 & 89,9 & 69,6 & 73,3 & 83,3 & 63 & 69,6 & 78,4 \\
\hline
\end{tabular}

Tabla 3. Caracterización geoquímica de obsidianas, mostrando elementos seleccionados en partes por millón (Stern et al., 2013). Nota: todas las muestras corresponden a desechos de talla.

\begin{tabular}{|c|c|c|c|c|c|c|c|c|c|c|c|}
\hline Sitio & Código & Tipo & $\mathrm{Rb}$ & $\mathrm{Sr}$ & Y & $\mathrm{Zr}$ & $\mathrm{Nb}$ & Cs & $\mathrm{Ba}$ & $\mathrm{Hf}$ & $\mathrm{Pb}$ \\
\hline \multirow{4}{*}{ Taller } & CS-1404 & PDA1 & 194 & 30 & 29 & 128 & 25 & 10,3 & 225 & 5,6 & 20,8 \\
\hline & CS-1405 & PDA1 & 192 & 30 & 30 & 128 & 25 & 10,1 & 227 & 5,3 & 21,3 \\
\hline & CS-1406 & PDA1 & 189 & 30 & 30 & 127 & 26 & 9,9 & 225 & 5,0 & 20,2 \\
\hline & CS-1407 & PDA3c & 146 & 37 & 12 & 88 & 21 & 5,9 & 446 & 3,4 & 15,6 \\
\hline \multirow{2}{*}{ Cueva } & CS-1409 & PDA1 & 191 & 30 & 29 & 124 & 25 & 9,6 & 214 & 4,8 & 19,5 \\
\hline & CS-1410 & PDA2 & 218 & 7 & 39 & 148 & 30 & 11,3 & 34 & 6,2 & 21,7 \\
\hline
\end{tabular}

frecuencia, por ello se optó por llevar a cabo una cuantificación básica para discriminar restos de roedores y aves de los restos de mamíferos medianos a mayores (Tabla 4). Estos últimos no pueden ser identificados a nivel anatómico, ni a nivel taxonó- mico; salvo excepciones como la segunda falange de Lama guanicoe que fuera fechada. Evidencias de acción humana, como huellas de corte, no pudieron ser observadas debido al estado fragmentario de la muestra. Por lo anterior, sólo se cuantificó la can- 
Tabla 4. Material óseo fragmentado recolectado por unidad de muestreo (U: unidad, TG: tamiz grueso, TF: tamiz fino).

\begin{tabular}{|c|c|c|c|c|c|c|c|c|c|}
\hline \multirow{2}{*}{ Material óseo } & \multirow{2}{*}{ U2 } & \multicolumn{2}{|c|}{ U3 } & \multicolumn{2}{|c|}{ U4 } & \multicolumn{2}{|c|}{ U5 } & \multirow{2}{*}{ U6 } & \multirow{2}{*}{ Total } \\
\hline & & TG & $\mathrm{TF}$ & TG & $\mathrm{TF}$ & TG & $\mathrm{TF}$ & & \\
\hline $\begin{array}{c}\text { Mamíferos } \\
\text { (mediano/mayor) }\end{array}$ & 128 & 415 & 154 & 224 & 73 & 163 & 35 & 305 & 1497 \\
\hline \% Quemado & 18,8 & 33,7 & 46,8 & 34,4 & 19,2 & 20,9 & 17,1 & 21,6 & 28,9 \\
\hline Roedores y aves & 34 & 12 & 4 & 9 & 1 & 6 & 3 & 3 & 72 \\
\hline \% Quemado & 2,9 & 8,3 & 50 & 11,1 & 0 & 0 & 0 & 0 & 6,9 \\
\hline Total óseos & 162 & 427 & 158 & 233 & 74 & 169 & 38 & 308 & 1569 \\
\hline (\% Quemado) & $(21,7)$ & (42) & $(96,8)$ & $(45,5)$ & $(19,2)$ & $(20,9)$ & $(17,1)$ & $(21,6)$ & $(35,8)$ \\
\hline
\end{tabular}

tidad de material combustionado, en el entendido que no es un indicador determinante de accionar antrópico. Mientras que la combustión presenta valores importantes entre los restos óseos de mamíferos medianos y mayores (29\%), su incidencia en los restos de roedores y aves es mucho menor $(<7 \%)$. Lo anterior apoya que no se deba descartar el factor humano en la incorporación de una parte del conjunto arqueofaunístico.

Si bien esto no permite discriminar la temporalidad de la acción sobre los restos de fauna, ya que son evidentes las indicaciones de actividades subactuales en el sitio, sí sugiere que una parte no determinable de la fauna pudo ser depositada en las efímeras ocupaciones detectadas a partir de los fechados ${ }^{14} \mathrm{C}$.

\section{Arte rupestre}

El arte rupestre presente en el sitio conforma una de las evidencias más abundantes, aunque también de las más afectadas por la acción antró- pica destructiva y el natural desprendimiento de las paredes del abrigo. El arte rupestre registrado en el sitio de la Cueva Punta del Monte corresponde únicamente a pinturas. Entre éstas dominan largamente las pinturas de color rojo $(96,7 \%)$, lo que es consistente con pequeñas evidencias de pigmento $(\mathrm{N}=4)$ registradas en la unidad de muestreo 6 y con un percutor con huellas de pigmento en las inmediaciones de las unidades de recolección (Fig. 3). Las otras dos tonalidades presentes son negro (un negativo de mano) y blanco (dos negativos de mano).

El conjunto rupestre incluye un número mínimo de 93 elementos (en adelante: E) y un número mínimo total de 55 motivos (en adelante: M), entre simples y compuestos (Fig. 5). Entre los grupos de motivos observados (Fig. 6) se encuentran:

Abstractos $(E=55 / M=19)$ : corresponden a motivos de tipo circulares, subcirculares, subcirculares con línea transversal, alineaciones de manchas, y motivos de líneas rectas y complejas. Entre los 


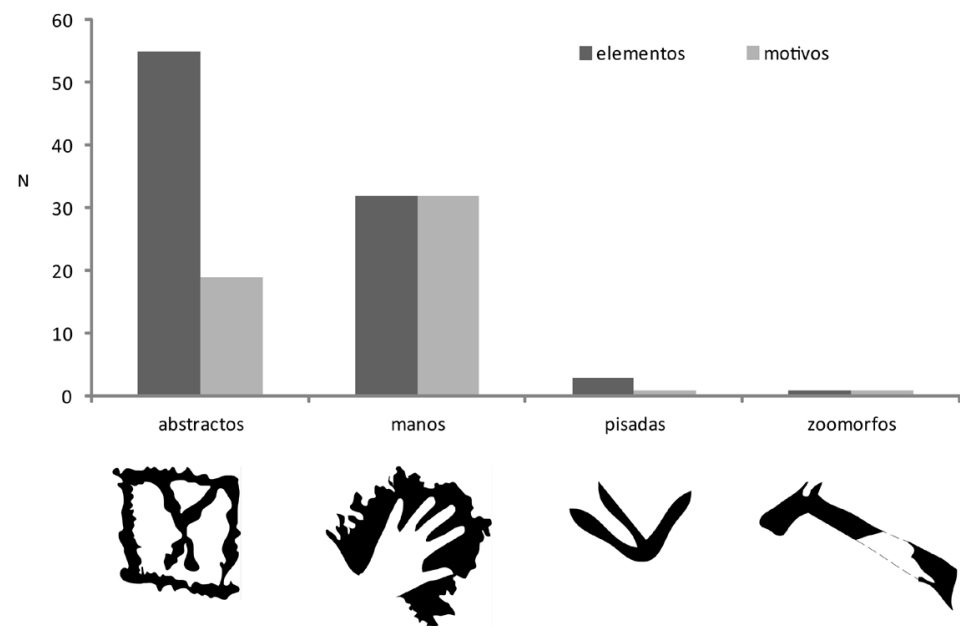

Fig. 5. Frecuencias de acuerdo a grupos de motivos rupestres

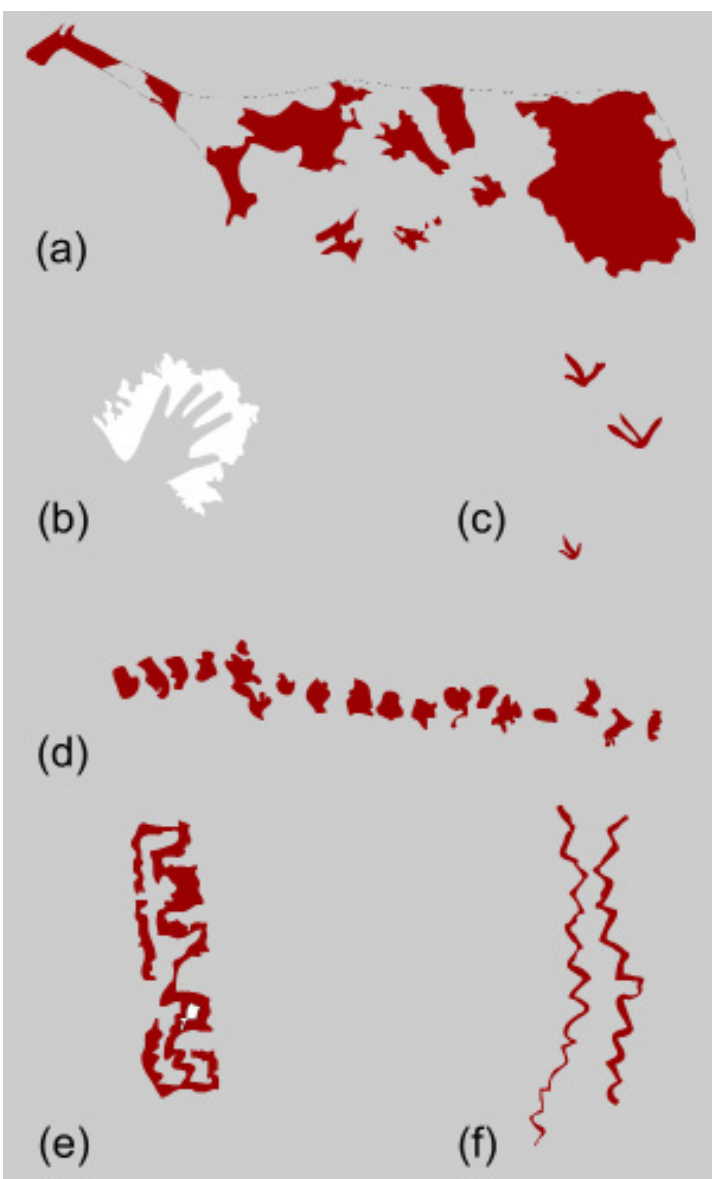

Fig. 6. Ejemplos de motivos rupestres del sitio Cueva Punta del Monte: (a) guanaco, (b) negativo de mano, (c) conjunto de tridígitos, (d)- (f) abstractos, (d) alineación de manchas, (e) peiniforme, (f) líneas quebradas. 


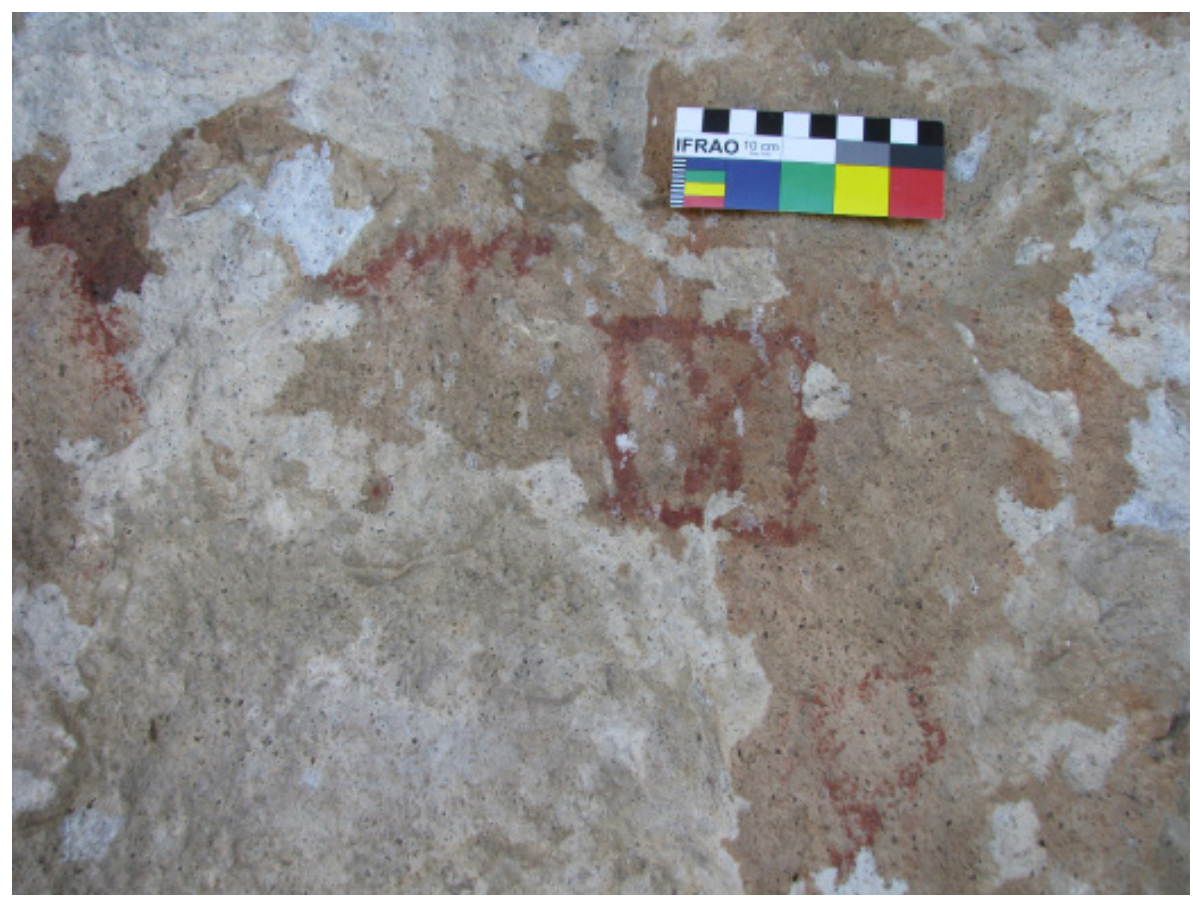

Fig. 7. Representaciones rupestres (abstractos) en Cueva Punta del Monte.

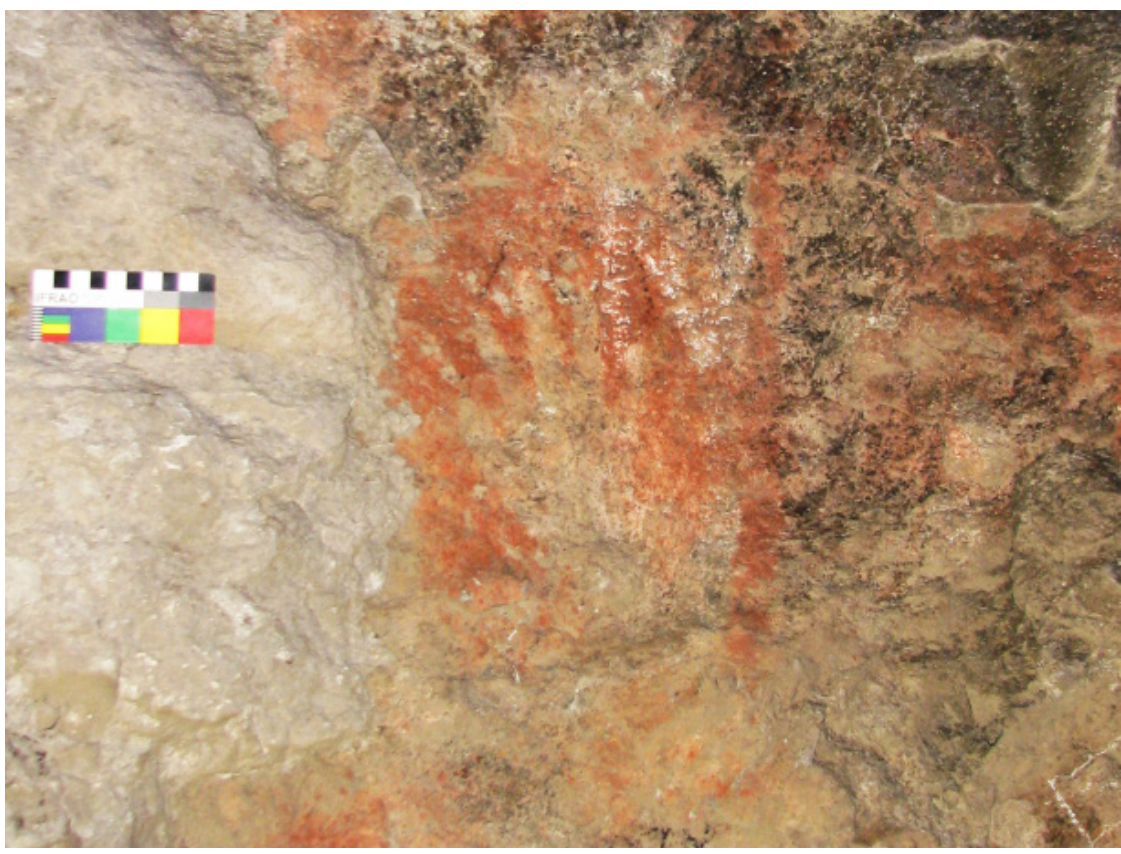

Fig. 8 Representaciones rupestres (negativos de manos) en Cueva Punta del Monte. 
motivos lineales se registraron: líneas quebradas, líneas rectas, motivos escalonados y elementos complejos de tipo peiniforme. Algunos de estos motivos lineales complejos pueden ser asociados a lo que se ha denominado como "estilo de Grecas" (Menghin, 1957; Bate 1970a; Gradín, 1978; Belardi, 2004). Pese a la variabilidad de elementos y motivos, todo este subconjunto es de color rojo (Fig. 7) .

Pisadas ( $E=3 / M=1)$ : en el caso de Punta del Monte, las pisadas se limitan a tridígitos o "pisadas de choique" las cuales aparecen asociadas en el mismo conjunto representando una continuidad alternada de tres elementos que asemeja los rastros dejados por el ave al caminar. Éstas son de color rojo.

Zoomorfos $(\mathrm{E}=1 / \mathrm{M}=1)$ : corresponde a un único caso de un guanaco de color rojo. Es probablemente unos de los motivos más deteriorados producto de los intensos intentos de fracturar la roca de soporte. Sin embargo, atributos distintivos como dos orejas, la forma del hocico, la forma y largo del cuello forma del hocico, la forma y largo del cuello, la morfología de la grupa, la relación entre las distintas partes y sus dimensiones hacen que supongamos de forma confiable que se trata de una representación de este animal. Dado el deterioro del motivo, no es posible asignarlo a ninguno de los estilos conocidos para las áreas cercanas (Gradín et al., 1987; Re 2010).

Manos $(E=34 / M=34)$ : corresponden exclusivamente a negativos de mano; 31 de color rojo, 2 de color blanco y 1 negra. No se consignó la altura específica para cada elemento. Sin embargo, se observó que la gran mayoría estaban entre 40 y $180 \mathrm{~cm}$ con respecto a la superficie; por lo que no involucrarían la necesidad de andamios para su ejecución. No obstante, dos manos blancas y dos rojas constituyen excepciones y se encuentran a ca. $200 \mathrm{~cm}$ de altura (Fig. 8). En la muestra estudiada dominan las manos izquierdas $(\mathrm{N}=14)$ por sobre las derechas $(\mathrm{N}=4)$, aunque el número de casos indeterminados es proporcionalmente alto $(\mathrm{N}=16)$. Resalta la ocurrencia de dos casos de manos pequeñas, las cuales se atribuyen tentativamente a niños.

Los agentes de deterioro de las pinturas son múltiples, extensivos y muy intensos. Ello impidió que se puedan discriminar intensidades de erosión diferencial entre las distintas unidades registradas. Similar es el caso para la evaluación de superposiciones y reciclado de motivos, ya que sólo se pudo observar superposición en el caso de un negativo de mano blanca sobre pintura roja. Por último, en relación al deterioro vale aclarar la alta frecuencia de rayados y graffitis, siendo éstos últimos en su mayoría números, nombres y líneas (v. grf. 1820, $1850,1920,1945,1980)$ hechos con tizne negro sobre las pinturas. También se observa en algunos casos el intento de hurto de pinturas a través de la extracción del soporte.

A los motivos de la Cueva de Punta del Monte, debiéramos sumar las manifestaciones rupestres registradas en un pequeño promontorio de la misma formación, ubicado a $47 \mathrm{~m}$ al Este de la cueva. En el mismo se observan dos motivos abstractos, uno compuesto por 14 líneas paralelas (muy delgadas) y el otro compuesto por un triángulo de líneas delgadas con una "X" inscrita de trazo grueso.

\section{DISCUSIÓN Y COMENTARIOS}

El objetivo principal de este trabajo consistió en sistematizar los resultados de las investigaciones llevadas a cabo en el sitio de la Cueva de Punta del Monte con el fin último de discutir su rol en la comprensión de la ocupación de los espacios de Aisén norte. Dos de las características más destacadas de la localidad de Punta del Monte son, en primer término, que se trata de un lugar elevado ( 1.000 msnm) con cobertura boscosa al oriente de Los Andes y en segundo término, que la Cueva de Punta del Monte es el único gran abrigo rocoso registrado en la zona y con disponibilidad inmediata de agua. La ubicación de Punta del Monte en este sector de altura y frontera entre dos ambientes marcadamente contrastantes como son el bosque y la estepa, coloca a este sitio en una situación singular en términos de su posicionamiento espacial. Si bien es cierto no existen reconstrucciones ambientales locales que permitan dimensionar desde cuándo esta frontera estuvo disponible, el hecho que el estero donde se emplaza el sitio corra por una falla puede considerarse como una condicionante geomorfológica relevante para la distribución vegetacional.

Por otro lado, el hecho que la Cueva de Punta del Monte constituya el mayor abrigo rocoso de las inmediaciones, ofrece condiciones oportunas para la ocupación humana. Otras ofertas de reparo se encuentran más distantes (por ejemplo Baño Nuevo 1 [Mena \& Stafford, 2006; Reyes et al., 2012] a $14,2 \mathrm{~km}$ de distancia) o bien dentro del bosque. De 
hecho, un conjunto de cuatro reparos sobre la misma formación (BN11 a BN14) se han identificado a 15,5 $\mathrm{km}$ al interior del bosque y no presentan evidencia de ocupación humana. Tampoco presentan evidencia material una cueva (CYA04) y un afloramiento (CYA05) recientemente localizados en la estepa hacia el sur, a 8 y $11,3 \mathrm{~km}$, respectivamente. Ante la baja cantidad de reparos ocupados, nos parece que la Cueva de Punta del Monte debiera ser un apropiado indicador de la ocupación humana para el área.

Como ha sido presentado en este trabajo, la evidencia del sitio de la Cueva de Punta del Monte es variada e incluye tecnología lítica, registro arqueofaunístico, arte rupestre, información ${ }^{14} \mathrm{C}$ y material asociado a ocupaciones subactuales. A esta evidencia se suma la información de procesos de formación de sitio brindada por la excavación realizada. Ésta nos advierte que en el pasado el curso del estero Casa de Piedra habría ingresado al alero contribuyendo a la incorporación de sedimentos, como también a la potencial sustracción de material arqueológico. A los fines de esta discusión, no encontramos pertinente considerar la evidencia definitivamente asociada a las últimas ocupaciones del sitio, como son las estructuras pircadas, los fragmentos de vidrio y el registro malacológico. El resto de la evidencia analizada ha arrojado resultados diversos que nos permiten discutirla en el marco de las expectativas planteadas.

En principio y en relación al registro lítico, a pesar que la evidencia del mismo está altamente recortada a causa del coleccionismo subactual, los desechos de talla y microdesechos de retoque en superficie pueden ser informativos de las conductas llevadas a cabo. En primer lugar, el hecho que el material en superficie sea tan escaso y esté representando pocas etapas de la secuencia de producción de instrumentos, pareciera estar connotando el uso del abrigo para actividades distintas a las residenciales, en tanto éstas debieran haber producido mayor cantidad y diversidad de material. Su uso, por tanto, debe ser considerado como esporádico y de baja intensidad, conclusión similar a la alcanzada por Bate (1970a). Un punto llamativo de esta inferencia, es que se encuentra en disidencia con la alta cantidad de motivos rupestres en el sitio, frecuencia esperable en un espacio más ocupado. Otro factor a destacar es que pese a que el sitio se encuentra en las inmediaciones del bosque, se observó una total ausencia de instrumentos líticos relacionados con el aprovechamiento de maderas. En sitios como El Deshielo (cuenca del río Cisnes), asociado a un ambiente de transición bosque/estepa y ubicado a $94 \mathrm{~km}$ de Punta del Monte, esta evidencia es muy abundante (Méndez et al., 2010). Las actividades de procesamiento de madera son altamente consumidoras de materias primas líticas y requieren gran cantidad de reemplazo (Hayden 1978). Aunque en el caso de la Cueva de Punta del Monte se debe contemplar la posibilidad que estos instrumentos hayan sido extraídos del sitio; debe tenerse en cuenta que la talla de piezas grandes para el procesamiento de maderas genera abundantes desechos, los que están muy bajamente representados en el sitio. Por último, el tercer factor a recalcar refiere a la presencia de obsidianas provenientes de Pampa del Asador (Stern et al., 2013), ubicada a aproximadamente $300 \mathrm{~km}$ de distancia en dirección sur de la localidad de Punta del Monte (Espinosa \& Goñi, 1999; Goñi et al., 2013). Este aspecto sugiere que los ocupantes de la Cueva y Taller de Punta del Monte participaron de circuitos de circulación de bienes que incluían áreas en la estepa, los que se han propuesto que estuvieron en funcionamiento desde el Holoceno temprano y fueron similares a lo largo del tiempo (Méndez et al., 2012).

El segundo conjunto de evidencia es el registro óseo. Al igual que el material lítico, actividades permanentes y reiteradas debieron haber producido mayor cantidad de evidencia arqueofaunística. Es cierto que la frecuencia y supervivencia de restos óseos depende de condiciones tafonómicas (Lyman, 1994), sin embargo, los restos fechados, se encontraban en óptimo estado de preservación. Esto sugiere que de haber habido mayor incorporación de restos óseos al contexto, una proporción reconocible habría sobrevivido.

Otro conjunto de evidencia está constituido por el arte rupestre, representado en su mayoría por los negativos de manos color rojo. Su ocurrencia es significativa en la escala espacial regional por cuanto la distribución del arte rupestre en Aisén es muy heterogénea. Al sur de Punta del Monte las manifestaciones rupestres poseen una frecuencia más alta, y son especialmente conocidas en la zona del río Ibáñez (Bate 1970a; Lucero \& Mena, 2000; Muñoz, 2013) y en menor medida para el Jeinemeni (Niemeyer, 1979-80). Por su parte, hacia el norte, 
los sitios con arte rupestre son más infrecuentes y la cantidad de motivos por panel es mucho menor (Baño Nuevo 1: Bate, 1979; Alero Las Quemas: Méndez \& Reyes, 2006; Lago Verde: Reyes, 2003). Esto hace suponer que esta localidad corresponde a la concentración rupestre más septentrional conocida de la región, lo que también tiene un correlato de límite. Adicionalmente, en la Cueva de Punta del Monte pueden diferenciarse tipos de motivos. En primer lugar, el motivo correspondiente al guanaco se encuentra muy deteriorado lo que no permite establecer comparaciones con estilos definidos en áreas vecinas (Gradín et al., 1987). Por otro lado, al igual que en la Cueva de Punta del Monte, en el área del Río Ibáñez los negativos de manos, aunque principalmente manos derechas, constituyen el motivo más frecuente (Lucero \& Mena, 2000). En esta zona las fechas más tempranas disponibles corresponden a los 6.050 años cal AP (Mena, 1983), siendo el límite máximo para las manifestaciones rupestres. De acuerdo a ello y a otros fechados del área, Lucero \& Mena (2000) han propuesto que los negativos de manos debieran asignarse a una cronología que se inicia hacia los 5.050 años cal AP (4.500 años AP) y se extiende hasta el final de la ocupación humana del valle. El límite cronológico propuesto por los autores se aproxima al fechado más temprano discutido en este trabajo para la Cueva Punta del Monte. Finalmente, los motivos de tipo lineal complejo, similares a algunos de los registrados en Punta del Monte, son propios de momentos tardíos no superiores a los últimos mil años y de gran dispersión en Patagonia (Belardi, 2004).

Los trabajos realizados en la Cueva de Punta del Monte han permitido, a partir de la integración de las líneas de evidencia, identificar ocupaciones humanas enmarcadas -con una fecha máxima- en los últimos 5.660 años. Dadas las características de esta evidencia, las implicancias que se deducen de ella son de carácter preliminar y deben ser consideradas como fuentes para preguntas de investigación. Aun así, las ocupaciones registradas fueron de muy baja intensidad, lo que se expresa en las bajas frecuencias de descarte (lítico, óseo, carbón), incluso considerando los sesgos producidos por el coleccionismo subactual. Si bien no es posible caracterizar si las ocupaciones fueron discontinuas en el tiempo dada la poca confiabilidad que ofrecen los contextos de los fechados, las pocas edades ${ }^{14} \mathrm{C}$ disponibles no se agrupan. Las evidencias no permitieron establecer función de sitio, sin embargo, sí admitieron descartar un uso residencial del sitio. Y por otra parte, fue posible desestimar una orientación hacia la explotación de maderas, situación teóricamente presumible en este tipo de ambientes. Así, las evidencias de Punta del Monte, aunque deben considerarse en el marco de una investigación muy preliminar, cumplen con las expectativas para caracterizar áreas marginales planteadas en diversos trabajos (Veth, 1993; Borrero, 2004; Neme \& Gil, 2008) en este caso traducidas a la escala de sitio. Es necesario considerar, sin embargo, que el sitio taller de Punta de Monte ha producido una enorme cantidad de evidencias líticas y que su diversidad de categorías tecnológicas representa una amplia variabilidad de actividades. Dadas las condiciones de deflación y la naturaleza superficial de los hallazgos no es posible sino considerar a todo el conjunto como un registro promediado sin posibilidades de precisar su asociación con las ocupaciones de la cueva.

A la luz de las características descritas, parece apropiado discutir las evidencias de Punta del Monte bajo la hipótesis que el sector haya sido de uso marginal. Los márgenes sólo pueden ser entendidos como la resultante de una jerarquización del espacio, donde otros sectores muestren mayor frecuencia de evidencias arqueológicas y por tanto, que concentraran mayor número de ocupaciones en el pasado. Sin ir más lejos, las evidencias de Baño Nuevo 1 señalan que la cueva fue redundantemente ocupada desde 10.740 cal AP y que incluso en algunos momentos la intensidad de señal humana fue muy alta, como lo sugiere la presencia de restos óseos de diez individuos fechados entre 10.200 y 9.700 cal AP (Mena \& Stafford, 2006; Reyes et al., 2012; Méndez et al., 2013a). En este sentido, estamos muy lejos aún de poder dimensionar la variabilidad del uso del espacio en una perspectiva temporal. Sin embargo, algunas evidencias recuperadas en Punta del Monte pueden considerarse indicativas de límites o fronteras, por ejemplo, la desigual distribución geográfica del arte rupestre que cambia drásticamente hacia el norte de Punta del Monte o el hecho que las obsidianas identificadas provengan de áreas de estepa abierta al Sur. El estudio de este tipo de fronteras ecológicas permite poner de relieve registro arqueológico en frecuencias 
bajas, esporádicas y de difícil diagnóstico, que a la larga posibilitan caracterizar la diversidad de formas en que el ser humano organizó jerárquicamente el espacio habitado.

\section{AGRADECIMIENTOS}

Financiado por FONDECYT \#1130128. Agradecemos el apoyo en uno de los fechados de NSF Arizona AMS Facility (University of Arizona). Se agradece al Sr. Juan Carrasco por los permisos para trabajar en la Cueva de Punta del Monte, así como al Sr. Alejandro Galilea y Estancia Punta de Monte y al Sr. Claudio Bariggi y Estancia Baño Nuevo por las facilidades y permisos otorgados para nuestro trabajo. Agradecemos a Francisco Mena, Pablo González, Catalina Contreras, Rodrigo Loyola, María Luisa Gómez, Ricardo Labra, Mónica Barrera, Valentina Varas, Eduardo Rebolledo, Cynthia Ziehlmann y a Charles Stern por su ayuda en labores de terreno y laboratorio. Agradecemos también a Anahí Ré y a Andrés Troncoso por sus comentarios a una versión anterior de este manuscrito.

\section{BIBLIOGRAFÍA}

Anderson, A. (2003). Entering uncharted waters. Models of initial colonization in Polynesia. En M. Rockman, \& J. Steele (Eds.), Colonization of unfamiliar landscapes (pp. 169-189). London: Routledge.

Aschero, C. A., \& Martel A. R. (2003-2005). El arte rupestre de Curuto-5, Antofagasta de la Sierra (Catamarca, Argentina). Cuadernos del INAPL, 20, 47-72.

Barberena, R., Hajduk A., Gil, A. F., Neme G. A., Durán, V., Glascock, M., \& Rughini, A. (2011). Obsidian in the south-central Andes: geological, geochemical, and archaeological assessment of north Patagonian sources (Argentina). Quaternary International, 245, 25-36.

Bate, L. F. (1970a). Primeras investigaciones sobre el arte rupestre de la Patagonia chilena. Anales del Instituto de la Patagonia, 1(1), 15-25.

Bate, L. F. (1970b). El yacimiento de Punta del Monte. Rehue, 3, 9-21.

Bate, L. F. (1979). Las investigaciones sobre los cazadores tempranos en Chile Austral. Trapananda, 1(2), 14-23.

Bate, L. F. (1982). Orígenes de la comunidad primitiva en Patagonia. México D.F.: Cuicuilco.

Belardi, J. B. (2004). Más vueltas que una greca. En M. T. Civalero, P. M. Fernández, \& A. G. Guráieb (Eds.), Contra
Viento y Marea. Arqueología de Patagonia (pp. 591603). Buenos Aires: Instituto Nacional de Antropología y Pensamiento Latinoamericano-SAA.

Borrero, L. A. (2004). The archaeozoology of Andean 'dead ends' in Patagonia: living near the continental ice cap. En M. Mondini, A. S. Muñoz, \& S. Wickler (Eds.), Colonisation, migration and marginal areas. A zooarchaeological approach (pp. 55-61). Oakville: Oxbow Books.

Bronk Ramsey, C. (2009). Bayesian analysis of radiocarbon dates. Radiocarbon, 51(1), 337-360.

Espinosa, S., \& Goñi R. A. (1999). Viven: una fuente de obsidiana en la provincia de Santa Cruz. En J.B. Belardi, P. M. Fernández, R. A. Goñi, A. G. Guráieb, \& M. De Nigris (Eds.), Soplando en el Viento, Actas de las III Jornadas de Arqueología de la Patagonia (pp. 177-188). Buenos Aires: Instituto Nacional de Antropología y Pensamiento Latinoamericano.

Goñi, R. A., Cassiodoro, G., \& Rindel, D. (2013). Poblamiento de mesetas: arqueología de Pampa del Asador y Cerro Pampa (Patagonia Meridional). Cuadernos del INAPL, 23. En prensa.

Gradín, C. (1978). Algunos aspectos del análisis de las manifestaciones rupestres. Revista del Museo Provincial, 1, 120-133

Gradín, C., Aschero, C., \& Aguerre, A. (1987). Primeros niveles culturales en el área río Pinturas (Provincia de Santa Cruz, Argentina). Estudios Atacameños, 8, 118-141.

Hayden, B. (1978). Snarks in Archaeology: or, inter-assemblage variability in lithics (a view from the Antipodes). En D. Lewis (Ed.), Lithics and subsistence; the analysis of stone tool use in prehistoric economies (pp. 179198). Nashville: Vanderbilt University Publications in Anthropology 20.

Hogg, A., Hua, Q., Blackwell, P.G., Niu, M., Buck, C.E., Guilderson, T.P., Heaton, T.J., Palmer, J.G., Reimer, P.J., Reimer, R.W., Turney, C.S.M., \& Zimmerman, S.R.H. (2013). SHCAL13 Southern Hemisphere Calibration, 0-50,000 years CAL BP. Radiocarbon 55(4), 1889-1903.

Lucero, V., \& Mena, F. (2000). Arte rupestre del Río Ibáñez (XI Región): un análisis cuantitativo exploratorio. En J.B. Belardi, F. Carballo, \& S. Espinosa (Eds.), Desde el País de los Gigantes. Perspectivas arqueológicas en Patagonia, Tomo 2 (pp. 415-427). Río Gallegos: UNPA.

Luebert, F., \& Pliscoff, P. (2006). Sinopsis bioclimática y vegetacional de Chile. Santiago: Editorial Universitaria.

Lyman, R. L. (1994). Vertebrate taphonomy. Cambridge manuals in archaeology. Cambridge: Cambridge University Press.

Mena, F. (1983). Excavaciones arqueológicas en cueva Las Guanacas (RI-16) XI Región de Aysén. Anales del Instituto 
de la Patagonia, 14, 67-75.

Mena, F. \& Stafford, T. (2006). Contexto estratigráfico y fechación directa de esqueletos humanos del Holoceno Temprano en Cueva Baño Nuevo 1 (Patagonia Central, Chile). En J. Jiménez, S. González, J. Pompa, \& F. Ortíz (Eds.), Segundo Simposio Internacional del Hombre Temprano en América (pp. 139-54). Ciudad de México: INAH.

Méndez, C., Barberena, R., Reyes, O., \& Nuevo Delaunay, A. (2013a). Isotopic ecology and human diets in the forest-steppe ecotone, Aisén Region, Central-Western Patagonia, Chile. International Journal of Osteoarchaeology. doi: 10.1002/oa.2337.

Méndez, C., \& Reyes, O. (2006). Nuevos datos de la ocupación humana en la transición bosque estepa en Patagonia: Alero Las Quemas (Comuna de Lago Verde, XI Región de Aisén). Magallania, 34(1), 161-165.

Méndez, C., \& Reyes, O. (2008). Late Holocene human occupation of Patagonian forests: a case study at Cisnes River basin (44으. Chile). Antiquity, 82, 560-570.

Méndez, C., Reyes, O., Nuevo Delaunay, A., \& Contreras, C. (2010). Criterios para evaluar ocupaciones tempranas en sitios arqueológicos superficiales, Aisén norte, Chile. En J. R. Bárcena, \& H. Chiavazza (Eds.), Arqueología argentina en el Bicentenario de la Revolución de Mayo, Tomo I (pp. 85-90). Mendoza: Universidad de Cuyo.

Méndez, C., Reyes, O., Nuevo Delaunay, A., Trejo, V., Barberena, R., \& Velásquez, H. (2011). Ocupaciones humanas en la margen occidental de Patagonia Central: eventos de poblamiento en Alto Río Cisnes. Magallania, 39, 223-242.

Méndez, C., Stern, C., Reyes, O., \& Mena, F. (2012). Early Holocene long-distance obsidian transport in CentralSouth Patagonia. Chungara Revista de Antropología Chilena, 44(3), 363-375.

Méndez, C., Reyes, O., Nuevo Delaunay, A., \& González, P. (2013b). Programa de búsqueda sistemática de evidencias tempranas y hallazgo de una punta de proyectil tipo cola de pescado en Alto Río Ñirehuao. Magallania, 41(2), 187-196.

Menghin, O. (1957). Estilos del arte rupestre de Patagonia. Acta Praehistorica, 1, 57-87.

Muñoz, C. (2013). Caracterización de los sitios ubicados en el río Ibáñez, XI región de Aisén, Chile: una aproximación a la relación arte rupestre-asentamiento. En A. F. Zangrando, R. Barberena, A. Gil, G. Neme, M. Giardina, L. Luna, C. Otaola, S. Paulides, L. Salgán, \& A. Tivoli (Eds.), Tendencias teórico-metodológicas y casos de estudio en la arqueología de la Patagonia (pp. 203-211). Buenos Aires: Museo de Historia Natural de San Rafael-
Sociedad Argentina de Antropología-Instituto Nacional de Antropología y Pensamiento Latinoamericano.

Neme, G. A., \& Gil, A. F. (2008). Biogeografía humana en los andes meridionales: tendencias arqueológicas en el sur de Mendoza. Chungara Revista de Antropología Chilena, 40(1), 5-18.

Niemeyer, H. (1979-80). La cueva con pinturas indígenas del río Pedregoso. Trapananda, 2(3), 7-21.

$\mathrm{Re}, \mathrm{A}$. (2010). Representaciones rupestres en mesetas altas de la Provincia de Santa Cruz. Circulación de información en espacios de uso estacional. Tesis Doctoral, Facultad de Filosofía y Letras. Buenos Aires: Universidad de Buenos Aires.

Re, A., Goñi, R. A., Belardi, J. B., \& Nuevo Delaunay, A. (2006/2007). Variabilidad de representaciones rupestres en el sector sur de la meseta del Strobel (Provincia de Santa Cruz). Cuadernos del Instituto Nacional de Antropología y Pensamiento Latinoamericano, 21, 215-226.

Reyes, O. (2003). Evaluación de los sitios arqueológicos descubiertos en los sectores de Planicie y Semillero, curso superior valle de Lago Verde, cuenca hidrográfica del Río Palena. Región de Aisén. Informe a la I. Municipalidad Lago Verde. Santiago, MS.

Reyes, O., Méndez, C., Mena, F., \& Moraga, M. (2012). The bioanthropological evidence of a CA. 10,000 CALYBP ten-individual group in central Patagonia. En L. Miotti, M. Salemme, N. Flegenheimer, \& T. Goebel, Southbound: Late Pleistocene peopling of Latin America (39-44). College Station: Center for the Study of the First Americans.

Sade, K. (2008). Cazadores extintos de Aysén continental. Coyhaique: Ediciones Nire Negro.

Stern, C., Castro, A., Pérez De Micou, C., Méndez, C., \& Mena, F. (2013). Circulación de Obsidianas en Patagonia Central-Sur entre 44 y $46^{\circ} \mathrm{S}$. En A. F. Zangrando, R. Barberena, A. Gil, G. Neme, M. Giardina, L. Luna, C. Otaola, S. Paulides, L. Salgán, \& A. Tivoli (Eds.), Tendencias teórico-metodológicas y casos de estudio en la arqueología de la Patagonia (pp. 245-250). Buenos Aires: Museo de Historia Natural de San Rafael-Sociedad Argentina de Antropología-Instituto Nacional de Antropología y Pensamiento Latinoamericano.

Veth, P. (1993). Islands in the interior: The dynamic of prehistoric adaptations within the arid zone of Australia. Michigan: International Monographs in Prehistory, Archaeological Series 3. 
Williams, A., Santoro, C., Smith, M., \& Latorre, C. (2008). El impacto de ENSO en el desierto de Atacama y la zona árida de Australia: análisis exploratorios de series temporales arqueológicas. Chungara Revista de Antropología Chilena, 40 (número especial), 245-259. 
A. NUEVO DELAUNAY et al. 